\title{
PARTIÇÃO DA PRECIPITAÇÃO PLUVIAL EM UMA MICROBACIA HIDROGRÁFICA OCUPADA POR MATA ATLÂNTICA NA SERRA DA MANTIQUEIRA, MG
}

\author{
PARTITIONING OF PLUVIAL PRECIPITATION IN A WATERSHED OCCUPIED BY ATLANTIC \\ FOREST IN MANTIQUEIRA RANGE, MG STATE
}

\author{
Léo Fernandes Ávila ${ }^{1}$ Carlos Rogério de Mello ${ }^{2}$ Leandro Campos Pinto ${ }^{3}$ Antônio Marciano da Silva ${ }^{4}$
}

\section{RESUMO}

A análise do comportamento da precipitação e sua interação nas diferentes etapas do ciclo hidrológico em bacias hidrográficas florestadas são essenciais para a determinação do balanço hídrico, devido à sua relevante participação nos processos hidrológicos e à sua variação espaço-temporal em função de fatores edáficos, topográficos, climáticos e de vegetação. Devido à heterogeneidade da Mata Atlântica, aliada à variabilidade espaço-temporal da precipitação, tornam-se fundamentais mecanismos que permitam a descrição, bem como a interligação dos componentes do balanço hídrico nesse ambiente. Nesse contexto, este estudo foi realizado com o objetivo de analisar a partição da precipitação pluvial em uma microbacia hidrográfica inteiramente ocupada por um remanescente de Mata Atlântica, durante os anos hidrológicos de 2009-2010 e de 2010-2011, correlacionando-a com a evolução sazonal dos ecossistemas, identificada pela aplicação das diferenças dos índices de vegetação por diferença normalizada (IVDN). Observou-se maior percentual de precipitação interna em períodos com menores precipitações. Constatou-se também maior capacidade de armazenamento de água do dossel vegetativo da Mata Atlântica no período chuvoso. Ainda, foi verificada correlação entre a capacidade de armazenamento de água do dossel da Mata Atlântica e a regeneração vegetal sinalizada pelo IVDN, podendo-se associar este comportamento aos processos responsáveis pelo desenvolvimento da Mata Atlântica.

Palavras-chave: IVDN; interceptação; precipitação pluvial; dossel florestal.

\begin{abstract}
The analyze of pluvial precipitation and its interaction on the different hydrologic cycle phases in forested watersheds are essential in order to water balance characterization due to its relevant participation in the hydrological processes and to its spatial-temporal variability as function of edaphic, topographic, climatic and vegetation elements. Due to heterogeneity of Atlantic Forest associated to temporal and spatial variability of pluvial precipitation regime, the study of mechanisms that allow describing and linking the hydrological cycle elements are very important. This way, the objective of this study was to analyze the partitioning of pluvial precipitation at a micro-catchment entirely occupied by Atlantic Forest remnant, in Mantiqueira Range, during 2009/2010 and 2010/2011 hydrological years, relating it with the seasonal evolution of this ecosystem which was monitored by the application of normalized difference vegetation indexes (NDVI). It was observed greater percentage of internal pluvial precipitation during the periods with less rainfall. It was also verified greater water storage capacity of the Atlantic Forest's canopy throughout rainy season. Yet, a plausible correlation was obtained between water storage capacity of Atlantic Forest and the regeneration of
\end{abstract}

1 Engenheiro Agrícola, Dr., Pesquisador do Programa Nacional de Pós-Graduação, Universidade Federal de Lavras, Caixa Postal 3037, CEP 37200-000, Lavras (MG), Brasil. avilalf@gmail.com

2 Engenheiro Agrícola, Dr., Professor Adjunto do Departamento de Engenharia Agrícola, Universidade Federal de Lavras, Caixa Postal 3037, CEP 37200-000, Lavras (MG), Brasil. crmello@deg.ufla.br

3 Engenheiro Agrícola, Doutorando pelo Programa de Pós-Graduação em Ciência do Solo, Universidade Federal de Lavras, Caixa Postal 3037, CEP 37200-000, Lavras (MG), Brasil. leandcampos@yahoo.com.br

4 Engenheiro Agrônomo, Dr., Professor Titular do Departamento de Engenharia Agrícola, Universidade Federal de Lavras, Caixa Postal 3037, CEP 37200-000, Lavras (MG), Brasil.marciano@ufla.br

Recebido para publicação em 23/02/2012 e aceito em 4/04/2013

Ci. Fl., v. 24, n. 3, jul.-set., 2014 
vegetation demonstrated by NDVI what can be associated to the processes responsible for Atlantic Forest's growth.

Keywords: NDVI; interception; pluvial precipitation; canopy forest.

\section{INTRODUÇÃO}

Os ecossistemas florestais atuam de forma significativa no ciclo hidrológico uma vez que interferem diretamente na redistribuição da chuva e, consequentemente, na parcela de água que contribui para a recarga dos aquíferos bem como na parcela que retorna para a atmosfera. Dentre os ecossistemas florestais, a floresta nativa é o que atua de forma mais expressiva no balanço hídrico devido à sua biodiversidade, complexidade do sistema e a própria dinâmica das comunidades dos fragmentos.

Estudos visando analisar os efeitos ocasionados pela conversão de florestas nativas por pastagem revelaram importantes mudanças no ciclo hidrológico (GRIP et al., 2004). As principais mudanças constatadas foram alteração da magnitude dos valores da parcela interceptada e da evaporação da superfície florestal (DIETZ et al., 2006). De acordo com Diáz et al. (2007), alterações na floresta nativa podem ocasionar mudanças nas características climáticas locais, alterando o processo de transferência de água para atmosfera. $\mathrm{Li}$ et al. (2009), estudando a sensibilidade hidrológica do solo em uma região no Oeste da África, observaram que o desmatamento total da área com florestas tropicais aumentou a taxa de escoamento superficial direto de $0,15 \%$ a $0,44 \%$.

No contexto hidrológico, dentre as importâncias que a floresta nativa desempenha, destacam-se: a formação de novas massas atmosféricas úmidas através das perdas por interceptação pelo dossel florestal, a qual contribui para o processo de precipitação; a influência positiva sobre a hidrologia do solo, melhorando os processos de infiltração, percolação e armazenamento de água; participação da vegetação herbácea e da matéria orgânica que recobre a superfície do solo, atuando na dissipação da energia cinética das gotas das chuvas, com redução do processo de erosivo e atenuação das vazões máximas. Além destes aspectos, a floresta nativa exerce importante papel na redução dos efeitos prejudiciais ao meio ambiente, como alteração da qualidade da água e eutrofização dos rios, dentre outros.

Segundo Diaz et al. (2007), o balanço hídrico em bacias hidrográficas constituídas por florestas nativas sofre grande influência em função da complexa estrutura das árvores, como porte elevado, densidade do dossel e fisionomia da planta. Entre os componentes do balanço hídrico de bacias hidrográficas constituídas por florestas nativas, a precipitação é considerada o principal elemento de equilíbrio (HERBST et al., 2006).

Assim, do total precipitado em florestas nativas, uma parcela significativa é interceptada pelo dossel florestal e, posteriormente, devolvida à atmosfera por evaporação (HOLDER, 2004). Outra parcela atinge a superfície do solo, a qual é denominada de precipitação efetiva (DIÁZ et al. 2007), sendo caracterizada pelo somatório da precipitação interna e do escoamento nos troncos.

O particionamento da precipitação em florestas nativas tem sido amplamente estudado (LEVIA e FROST, 2006; DIETZ et al., 2006; STAELENS et al., 2008). Entretanto, devido à heterogeneidade dos ecossistemas florestais, a comparação dos aspectos relacionados à influência da estrutura do dossel florestal sobre o partição da precipitação é relativamente complexa (CROCKFORD e RICHARDSON, 2000; GERRITS et al., 2010). De modo geral, os fatores que influenciam na partição da precipitação em ecossistemas florestais estão relacionados às condições meteorológicas e biológicas (CROCKFORD e RICHARDSON, 2000).

As condições meteorológicas correspondem ao volume, à intensidade e à duração das chuvas, à taxa de evaporação, à velocidade do vento e ao intervalo entre os eventos (CROCKFORD e RICHARDSON, 2000). As condições biológicas referem-se a todas as características relacionadas às florestas, como arquitetura das plantas, estrutura e densidade do dossel, composição e heterogeneidade da comunidade das espécies, entre outros.

Neste aspecto, a densidade do dossel e a área foliar são consideradas os principais fatores envolvidos na capacidade de armazenamento de água no dossel das florestas (GASH et al, 1995), o que consequentemente influencia diretamente na partição da precipitação. Além destes fatores, a altura das plantas, associada à rugosidade do dossel 
das florestas, pode influenciar na transferência de água para a atmosfera, interferindo no processo de interceptação (HOISCHER et al., 2004).

Além dos aspectos mencionados, os fatores experimentais, como a distribuição dos pluviômetros, o intervalo entre as coletas e a densidade amostral, influenciam indiretamente na partição da precipitação, dificultando a análise comparativa entre os diferentes locais pesquisados (CASTRO et al., 1983). Alguns autores destacam a necessidade de um elevado número de pluviômetros, entretanto, não existe um estudo que estabeleça uma metodologia suficientemente adequada para o monitoramento destas variáveis. Holwerda et al. (2006) concluíram que são necessários cem pluviômetros fixos para se obter resultado similar ao obtido com trinta pluviômetros móveis, com nível de confiança de $95 \%$.

Devido à relevância da dinâmica da distribuição espaço-temporal da vegetação, aliada à variabilidade espaço-temporal da precipitação, o entendimento dos mecanismos associados a estes processos é de fundamental importância. . Dessa forma, uma ferramenta que tem sido muito aplicada é o índice de vegetação por diferença normalizada - IVDN (TUCHER, 1979), o qual possibilita a distinção de diferentes características sazonais na fenologia da cobertura vegetal (WANG e TENHUNEM, 2004).

O IVDN tem sido considerado como um importante método para a classificação e monitoramento da vegetação (KOGAN, 1995), mostrando correlação plausível com a precipitação (NEZLIN et al., 2005) e com fenômenos climáticos em escala global (GURGEL e FERREIRA, 2003). Gurgel e Ferreira (2003), estudando a variabilidade anual e interanual de regiões brasileiras e o tempo de resposta do IVDN à precipitação, observaram resposta satisfatória deste índice, o qual apresentou um padrão bem definido em relação aos períodos chuvoso e seco.

Devido à alta diversidade dos ecossistemas do Brasil, especialmente em ambiente de Mata Atlântica, assim como a significativa variabilidade da magnitude dos valores de partição da precipitação, estudos visando ao entendimento deste processo em ecossistemas florestais são extremamente relevantes no contexto do gerenciamento e monitoramento ambiental em bacias hidrográficas florestadas, especialmente aquelas em regiões de cabeceira, como a Serra da Mantiqueira.

Assim, o presente estudo foi realizado com o objetivo de analisar a partição da precipitação em uma microbacia hidrográfica inteiramente ocupada por um remanescente de Mata Atlântica, da Serra da Mantiqueira, durante os anos hidrológicos de 2009-2010 e de 2010-2011, correlacionando-a com a evolução sazonal dos ecossistemas em ambiente de Mata Atlântica por meio do IVDN.

\section{MATERIAL E MÉTODOS}

\section{Aspectos gerais da área de estudo}

A Bacia Hidrográfica do Ribeirão Lavrinha (BHRL) corresponde a uma área experimental com monitoramento hidrológico e climático desde o ano de 2006. Está inserida no Bioma da Mata Atlântica e se localiza na região sudeste do estado de Minas Gerais, na Serra da Mantiqueira, próxima à divisa com o estado do Rio de Janeiro (Figura 1). Situa-se entre as coordenadas $22^{\circ} 07^{\prime} \mathrm{S}$ e $22^{\circ} 09^{\prime} \mathrm{S}$ de Latitude

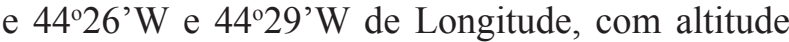
entre $1.144 \mathrm{~m}$ e $1.800 \mathrm{~m}$, com área de drenagem de aproximadamente 690 ha e declividade média de 35\%. Segundo Mello et al. (2012), seu clima com base nas metodologias de Köppen e Thorntwaite são, respectivamente, $\mathrm{Cwb}$ e Superúmido A. A temperatura média anual é de $16,0^{\circ} \mathrm{C}$, com a média das mínimas de $10^{\circ} \mathrm{C}$ e a média das máximas de $23^{\circ} \mathrm{C}$. Os totais médios anuais de precipitação verificados variaram de 1.841 a $2.756 \mathrm{~mm}$, com concentração média de $88,3 \%$ deste total entre setembro e março. Há um período seco característico, cujo início ocorre em abril e é finalizado em agosto, em condições normais.

No interior da BHRL encontra-se uma microbacia hidrográfica inteiramente ocupada por um remanescente de Mata Atlântica, a qual será referida, neste trabalho, como Microbacia Hidrográfica de Mata Atlântica (MBMA), com área aproximada de 16 ha (Figura 1). A MBMA possui altitudes variando entre 1.450 e $1.800 \mathrm{~m}$ e declividade média de $45 \%$. Seus solos são predominantemente Cambissolos Háplicos, com profundidade variando de 0,70 a $1,20 \mathrm{~m}$ e cujo material de origem consiste de gnaisse-granito (MENEZES et al. 2009). Suas características geomorfológicas são típicas da região da Serra da Mantiqueira, ou seja, solos pouco a moderadamente profundos, caracterizados por alta concentração de matéria orgânica e relevo variando de ondulado a forte ondulado e montanhoso (MENEZES, 2011; JUNQUEIRA JUNIOR et al., 2008). 
O remanescente de Mata Atlântica apresenta um estrato arbóreo denso, formando um dossel que atinge em média $8,75 \mathrm{~m}$ de altura e diâmetro médio a $1,3 \mathrm{~m}$ do solo (DAP) de $9,83 \mathrm{~cm}$. A fitofisionomia predominante na área é a Floresta Ombrófila Densa, sendo esta um típico remanescente de Mata Atlântica da Serra da Mantiqueira (OLIVEIRA FILHO et al., 2006), a qual é caracterizada por árvores de folhas largas, sempre verdes, de duração relativamente longa e mecanismos adaptados para resistir a períodos de elevadas temperaturas.

$\mathrm{Na}$ porção mais elevada e de maior declividade, encontram-se fragmentos de árvores remanescentes da vegetação primitiva, que podem alcançar mais de $10 \mathrm{~m}$ de altura. No restante, encontram-se fragmentos de árvores secundárias, com menor porte e com indícios de impactos antrópicos. As espécies de maior ocorrência estão apresentadas na Tabela 1.

\section{Monitoramento da precipitação incidente $(\mathrm{P}) \mathrm{e}$ precipitação interna $(\mathbf{P i})$}

Para quantificar a precipitação que atravessa o dossel vegetativo e atinge a superfície do solo (precipitação interna), foram instalados
25 pluviômetros do tipo Ville de Paris, os quais foram distribuídos no interior da Mata Atlântica (Figura 1), nivelados e colocados a uma altura de 1,50 $\mathrm{m}$ do solo (DIETZ et al., 2006; CUARTAS et al., 2007), com distância média em torno de $50 \mathrm{~m}$, de forma a representar a maior parte da estrutura do dossel da floresta. Loescher et al. (2002), para floresta tropical na Costa Rica, recomendaram um espaçamento entre medidores acima de $45 \mathrm{~m}$ para minimizar viés nas estimativas provocadas pelas copas das árvores. O período de monitoramento foi de outubro de 2009 a setembro de 2011. A precipitação interna foi monitorada no início do dia subsequente de cada evento de chuva.

A precipitação que atinge o dossel da mata (precipitação incidente) foi monitorada por meio de uma estação meteorológica programada para coletar dados com intervalo de 1 hora. A estação meteorológica foi instalada nas proximidades da MBMA, à distância de $30 \mathrm{~m}$ da área experimental (Figura 1).

Apesar de o escoamento pelo tronco apresentar relativa importância no ciclo hidrológico como forma eficiente de água no solo, este elemento não foi considerado neste estudo, uma vez que o objetivo foi o de analisar a interação entre as

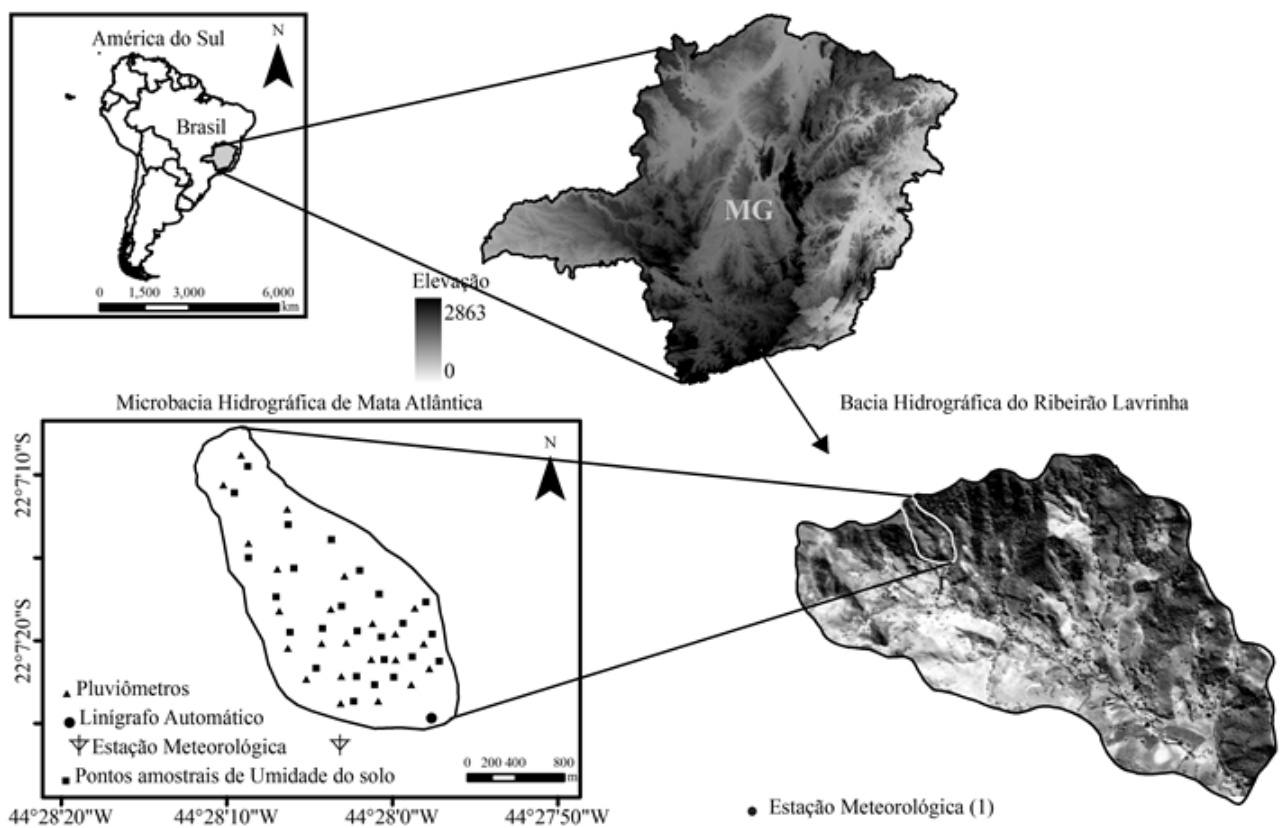

FIGURA 1: Localização geográfica e do instrumental usado no monitoramento hidrológico na MBMA, Serra da Mantiqueira, MG.

FIGURE 1: Geographical location and instrumentation used to hydrological monitoring of MBMA, Mantiqueira Range, MG state. 
TABELA 1: Espécies florestais de maior ocorrência na MBMA, Serra da Mantiqueira, MG.

TABLE 1: Forestry species of greater occurrence at MBMA, Mantiqueira Range, MG state.

\begin{tabular}{ll}
\hline \multicolumn{1}{c}{ Nome científico } & \multicolumn{1}{c}{ Nome popular } \\
\hline Tibouchina fothergillae (DC.) Cogn & Quaresmeira \\
Myrsine umbellata Mart. & Capororoca, Pororoca \\
Psychotria vellosiana Benth. & Café-do-mato \\
Clethra scabra Pers. & Carne-de-vaca, Vassourão \\
Guapira opposita (Vell.) Reitz & Maria-mole, Louro-branco \\
Myrcia splendens (Sw.) DC. & Guamirim, Guamirim-miúdo \\
Eremanthus erythropappus (DC.) MacLeisch & Candeia \\
\hline
\end{tabular}

precipitações incidente e interna, considerando as variações sazonais da precipitação no ano hidrológico.

Paraanalisara capacidade dearmazenamento de água do dossel florestal, procedeu-se à análise dos eventos de forma isolada, admitindo um intervalo entre eles de, no mínimo, 24 horas e precipitação incidente entre 1,5 e $20 \mathrm{~mm}$ (DAVID et al., 2002). Dessa forma, garante-se que o dossel florestal encontrava-se relativamente seco e próximo à sua capacidade máxima de armazenamento. Após a individualização das precipitações, ajustou-se uma regressão linear simples entre a precipitação interna (Pi) e a precipitação incidente $(\mathrm{P})$, considerandose os eventos obtidos nos dois anos hidrológicos monitorados, bem como a variação sazonal em cada um destes anos. A capacidade máxima de armazenamento do dossel consiste no valor de $\mathrm{P}$, quando Pi for igual a zero (CUARTAS, 2008).

\section{Índice de vegetação por diferença normalizada da Mata Atlântica (IVDN)}

Visando analisar as variações sazonais da vegetação de Mata Atlântica em resposta à variabilidade espaço-temporal da precipitação, o índice de vegetação por diferença normalizada foi utilizado, considerando os períodos seco e chuvoso, para os dois anos hidrológicos monitorados.

O IVDN é um indicador básico de alterações na vegetação ao longo do espaço e do tempo e tem sido amplamente empregado para descrição do índice de área foliar (TUCKER, 1979), quantificação da biomassa da floresta (SELLERS, 1993), dentre outros objetivos. Portanto, o IVDN indica as mudanças da fenologia da vegetação oriundas das variações sazonais da precipitação.
Dessa forma, durante períodos de regeneração vegetal, são registrados maiores valores de IVDN. Em contrapartida, períodos de perda de vegetação apresentam menores valores de IVDN (HUXMAN et al., 2004). Este comportamento ocorre devido à sensibilidade do IVDN à presença da vegetação, pois a vegetação sadia reduz a resposta no vermelho pela absorção de clorofila e aumenta a resposta no infravermelho próximo devido ao espalhamento pelos tecidos da folha (TUCKER e SELLERS, 1986). Dessa forma, alvos diferentes de vegetação (água, solo exposto, etc.) são facilmente distinguíveis devido às suas assinaturas espectrais características. Segundo Baret e Guyot (1991), o IVDN aumenta o contraste entre solo e vegetação e minimiza os efeitos das condições de iluminação, no entanto, é sensível às propriedades ópticas do solo.

Os valores de IVDN podem variar entre - $1 \mathrm{e}$ +1 . Assim, em superfícies com vegetação existente, o IVDN varia de 0 (escassez de vegetação) a 1 (totalmente ou parcialmente vegetada). Para água e nuvens, o IVDN é menor que zero.

Para esta análise foram utilizadas imagens disponibilizadas pelo Instituto Nacional de Pesquisas Espaciais (INPE). O sensor utilizado foi o TM (Thematic Map) do satélite LANDSAT 5 com as bandas de números 4 e 3 correspondendo, respectivamente, ao espectro infravermelho próximo e vermelho. A cena que abrange a MBMA é a 218/75.

Foram utilizadas 6 imagens de satélite correspondentes às seguintes épocas: 24/04/09, 30/08/09, 27/04/10, 01/08/10, 14/04/11 e 04/08/11. Para escolha das épocas das imagens, considerou-se a ausência de nuvens e a inexistência de sombra. Além disso, procurou-se adquirir imagens de 
períodos próximos à mesma época do ano, uma vez que os períodos chuvoso e seco alteram sensivelmente o IVDN da cobertura vegetal.

Assim, após a aquisição das imagens, foi realizado o recorte na região de interesse, delimitando a MBMA. Em seguida, fez-se a transformação do número digital do pixel em radiância espectral. Para tanto, foi aplicada a seguinte equação, proposta por Chander e Markham (2007):

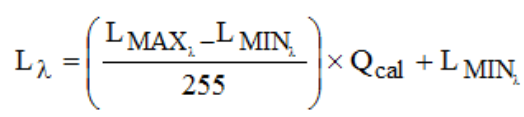

Em que $\mathrm{L}_{\lambda}=$ radiância espectral na banda, em $\mathrm{W} /\left(\mathrm{m}^{2} \cdot \mathrm{sr} \cdot \mu \mathrm{m}\right) ; \quad \mathrm{L}_{\mathrm{MAX \lambda}}=$ radiância espectral máxima na banda, em $\mathrm{W} /\left(\mathrm{m}^{2} . \mathrm{sr} . \mu \mathrm{m}\right) ; \mathrm{L}_{\mathrm{MIN}}=$ radiância espectral mínima na banda, em $\mathrm{W} /\left(\mathrm{m}^{2}\right.$. sr. $\mu \mathrm{m})$ e $\mathrm{Q}_{\text {cal }}=$ intensidade do pixel, adimensional. Os resultados de $\mathrm{L}_{\mathrm{MAX} \lambda}$ e $\mathrm{L}_{\mathrm{MIN} \lambda}$ foram extraídos de Chander e Markham (2007).

A partir da reflectância espectral, calculouse a reflectância aparente, a qual corresponde à taxa de radiação que foi captada pelo satélite em relação à radiação incidida no topo da troposfera, a partir da equação 1, adaptada por Chander e Markahm (2003) e Folhes (2007). Em seguida, calculou-se o IVDN por meio da razão entre a diferença da reflectância do infravermelho próximo $\left(r_{4}\right)$ e a do vermelho $\left(\rho_{3}\right)$, normalizada pela soma de ambas (ALLEN et al., 2002), para as 6 imagens adquiridas:

$$
\operatorname{IVDN}=\frac{\rho_{4}-\rho_{3}}{\rho_{4}+\rho_{3}}
$$

em que $r_{4}$ e $\rho_{3}$ correspondem, respectivamente, às reflectâncias das bandas $4 \mathrm{e}$ 3 do sensor TM Landsat 5.

Após a determinação do IVDN, calculouse a variação de IVDN, pixel a pixel, das imagens, considerando os períodos chuvoso e seco dos anos hidrológicos. Assim, para a variação de IVDN para o ano hidrológico $09 / 10$ foi considerado no período chuvoso, a diferença entre as imagens de 27/04/10 e 24/04/09 e no período seco, a diferença entre as imagens de 01/08/10 e 30/08/09. De forma similar, para o ano hidrológico $10 / 11$, considerouse, no período chuvoso, a diferença entre 14/04/11 e 27/04/10 e no período seco, a diferença entre 04/08/11 e 01/08/10. Assim, os produtos desta análise resultaram em quatro imagens, correspondendo aos períodos chuvoso e seco de cada ano hidrológico estudado.

Para análise da variação de IDVN, as imagens foram classificadas em função da média e do desvio padrão dos valores da diferença de IVDN, visando obter um índice que sinalize a perda e a regeneração da vegetação. Desta forma, a análise foi dividida em três classes, sendo a classe inferior correspondente à média subtraída do desvio padrão da diferença de IVDN, a qual sinaliza uma possível perda vegetal; a classe superior, correspondendo à média somada ao desvio padrão, sinalizando, por sua vez, uma possível regeneração da vegetação. A classe inferior, a qual indica sensível perda de vegetação, foi simbolizada com tonalidade cinzaclaro, enquanto a classe superior, indicando sensível regeneração, com tonalidade preta.

\section{RESULTADOS E DISCUSSÃO}

\section{Comportamento da precipitação incidente e da precipitação interna na MBMA no período analisado}

Ao longo do período monitorado (outubro de 2009 a setembro de 2011), foram registrados $4.949 \mathrm{~mm}$ de precipitação. O total registrado foi distribuído em 285 eventos, com grande amplitude de variação, sem nenhuma ocorrência no mês de agosto de 2010 e um total mensal de $928 \mathrm{~mm}$ em janeiro de 2011.

A precipitação interna total no respectivo período foi de $3.923 \mathrm{~mm}$, correspondendo a $79 \%$ da precipitação incidente total. Segundo Oliveira et al. (2008), para florestas tropicais, as variações da precipitação interna estão entre $75 \%$ e $96 \%$ da precipitação total incidente (acima do dossel). Oliveira e Dias (2005), avaliando a precipitação em um fragmento secundário de Mata Atlântica, constataram que o percentual de precipitação interna foi de $80 \%$ da precipitação incidente. Cardoso et al. (2002), trabalhando na mesma área, porém, com menor densidade amostral, verificaram que a precipitação interna correspondeu a $78 \%$ da incidente. Ferreira et al. (2005) obtiveram valores entre $74,2 \%$ e $87,1 \%$. Observa-se, portanto, que os resultados obtidos neste trabalho são semelhantes aos obtidos em outros estudos sobre o comportamento da precipitação e da interceptação em fragmentos de Mata Atlântica no Sudeste do Brasil.

Como o processo de redistribuição da chuva pela floresta é influenciado pela distribuição temporal das precipitações, os dados foram analisados considerando o padrão sazonal das precipitações. Dessa forma, os mesmos foram 
comparados considerando o período chuvoso (outubro a março) e o de estiagem (abril a setembro) dos anos hidrológicos 09/10 (período entre o mês de outubro de 2009 a setembro de 2010) e 10/11 (período entre o mês de outubro de 2010 a setembro de 2011)

Na Figura 2 apresenta-se a distribuição mensal da precipitação incidente e da precipitação interna, durante os anos hidrológicos 09/10 e 10/11. Observou- se elevada sazonalidade dos eventos, com um percentual médio de $91 \%$ para o período chuvoso (outubro a março) e $9 \%$ para o período seco (abril a setembro) da precipitação total anual referente aos dois anos hidrológicos. Percebe-se também semelhança no padrão do comportamento da precipitação incidente e da precipitação interna, mostrando um crescimento proporcional nos meses que caracterizam a estação chuvosa. Contudo, no período chuvoso do ano hidrológico 10/11, este padrão de comportamento da precipitação interna não foi observado, especialmente no início do período chuvoso (outubro de 2010), e no mês de fevereiro de 2011, quando se verifica que a parcela da precipitação interna foi significativamente maior se comparada aos respectivos meses do ano hidrológico 09/10.

Observa-se também maior magnitude dos valores de precipitação interna no período seco nos dois anos hidrológicos, mostrando-se um aumento expressivo da parcela da chuva que atravessa o dossel vegetativo e atinge a superfície do solo em épocas com menor ocorrência de precipitação. Este comportamento indica tendência de maior percentual de precipitação interna em épocas com menor total precipitado, podendo este fato ser associado à formação florestal semidecidual da mata, caracterizada por quedas das folhas nas estações secas que, ocasionalmente, provocaram a redução da área do dossel vegetativo e, consequentemente, menor interceptação da chuva, contribuindo assim para o aumento do percentual da precipitação interna.

A Figura 2B refere-se aos valores acumulados de precipitação incidente e interna para os períodos chuvoso e seco e o total acumulado para os dois anos hidrológicos. No ano hidrológico $09 / 10$ foi registrado um total de $2.220 \mathrm{~mm}$, sendo que, deste total, $1.940 \mathrm{~mm}(87 \%)$ ocorreram no período chuvoso e $280 \mathrm{~mm}$ no período seco (13\%). O mês de maior ocorrência foi dezembro de 2009, com $521 \mathrm{~mm}(23,5 \%)$ e o único mês em que não houve registro de precipitação foi agosto de 2010 .

A precipitação total incidente do ano hidrológico $10 / 11$ superou em $22 \%$ o total do ano hidrológico $09 / 10$, totalizando $2.728 \mathrm{~mm}$. No período chuvoso, o total precipitado correspondeu a $95 \%$ do ano hidrológico 10/11, com $2.568 \mathrm{~mm}$. Neste aspecto, constata-se que houve maior concentração de chuvas no período chuvoso deste ano hidrológico comparado ao ano 09/10 (87\%). Vale ressaltar que o mês janeiro de 2011 foi totalmente atípico, tendo sido registrados $928 \mathrm{~mm} \mathrm{(34 \%} \mathrm{do} \mathrm{total}$ precipitado no ano hidrológico 10/11), contribuindo significativamente para a concentração de chuvas neste período. Os eventos de precipitação referentes a este mês estavam associados à atuação de
A)

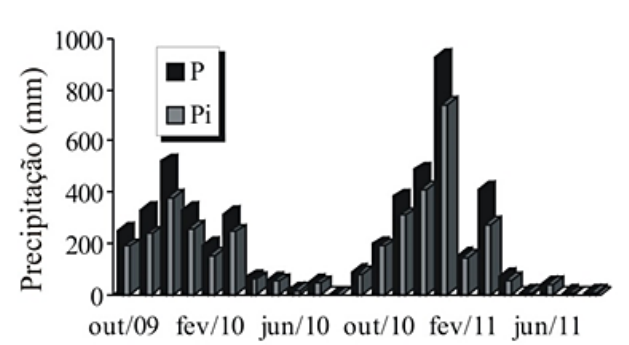

B)



FIGURA 2: Precipitação incidente (P) e precipitação interna (Pi) mensais observadas no período de outubro de 2009 a setembro de 2011 (A) e respectivos valores acumulados para os períodos chuvoso e seco e total acumulado para cada ano hidrológico (B).

FIGURE 2: Monthly precipitation (P) and throughfall precipitation (Pi) observed between October/09 and September/11 (A) and respective values accumulated during and rainy and dry seasons and total precipitation for each hydrological year (B). 
episódios sequenciais e extraordinários da Zona de Convergência do Atlântico Sul (INFOCLIMA, 2011). No período seco, o total precipitado foi de apenas $160 \mathrm{~mm}$ (5\% da precipitação incidente) e o mês com menor ocorrência foi agosto $(6 \mathrm{~mm})$.

Do percentual de precipitação concentrada nos períodos chuvoso e seco, $75 \%$ e $91 \%$, respectivamente, foram convertidos em precipitação interna. Do mesmo modo, no ano hidrológico 10/11, $81 \%$ e $79 \%$ se converteram em precipitação interna, respectivamente, nos períodos chuvoso e seco. Constata-se que o total de precipitação incidente no período seco $(280 \mathrm{~mm})$, do ano hidrológico de 09/10, foi consideravelmente maior que o total do período seco $(160 \mathrm{~mm})$ do ano hidrológico de 10/11, com diferença aproximada de $75 \%$. Verificase também maior parcela convertida da precipitação incidente no período seco do ano hidrológico 09/10, comparado ao ano hidrológico 10/11, em torno de $12 \%$.

No período chuvoso, verificou-se menor diferença entre os valores totais de precipitação incidente entre os dois anos hidrológicos em relação ao período seco, com $1.940 \mathrm{~mm}$ e $2.568 \mathrm{~mm}$, nos anos hidrológicos 09/10 e 10/11, respectivamente, com uma diferença de aproximadamente $32 \%$. Além disso, nota-se que a parcela convertida da precipitação incidente no período chuvoso do ano hidrológico $10 / 11$ foi consideravelmente menor (6\%) que a do mesmo período do ano hidrológico $09 / 10$.

De acordo com os resultados, observase maior variabilidade da parcela de precipitação incidente convertida em precipitação interna no período seco $(12 \%)$ comparada ao período chuvoso (6\%), entre os dois anos hidrológicos. Este comportamento sinaliza a ocorrência de maior variabilidade da magnitude dos valores de precipitação interna na estação seca. Assim, constata-se que houve diferenças significativas no padrão da precipitação interna em relação ao regime sazonal das precipitações, em termos da parcela convertida em precipitação interna e em função da dispersão da magnitude dos valores.

Capacidade de armazenamento de água do dossel vegetativo da Mata Atlântica na Serra da Mantiqueira, MG

Na Figura 3 estão apresentados os modelos lineares ajustados aos totais mensais de precipitação incidente e interna, considerando todo período monitorado (anos hidrológicos 09/10 e 10/11) e, os totais mensais correspondentes aos períodos chuvoso e seco dos dois anos hidrológicos em conjunto. $\mathrm{O}$ ajuste dos modelos apresentou alta correlação entre a precipitação incidente e a precipitação interna, podendo-se inferir que a precipitação interna pode ser explicada pela precipitação incidente.

Com base na equação linear apresentada na Figura 3A, correspondente ao ajuste dos dados de precipitação interna em função da incidente de toda série histórica monitorada, constatouse que precipitações inferiores a $1,58 \mathrm{~mm}$ são totalmente interceptadas pelo dossel da floresta e, posteriormente, transferidos para a atmosfera por evaporação. Oliveira Júnior e Dias (2005) verificaram que a capacidade de retenção de água das copas de um fragmento secundário de Mata Atlântica foi de 1,3 mm. Lima e Leopoldo (2000)
A)

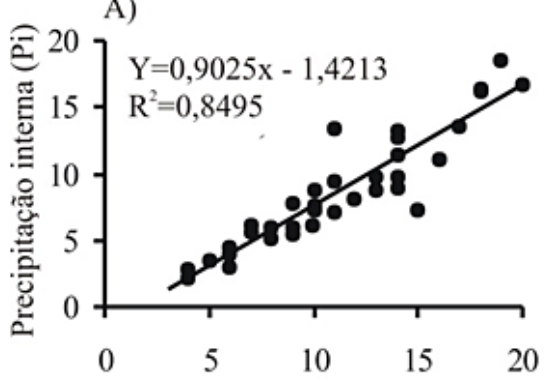

B)

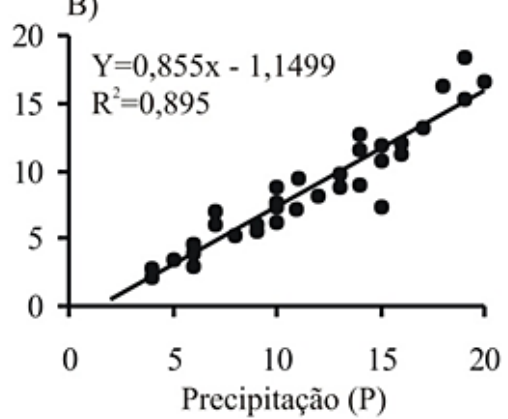

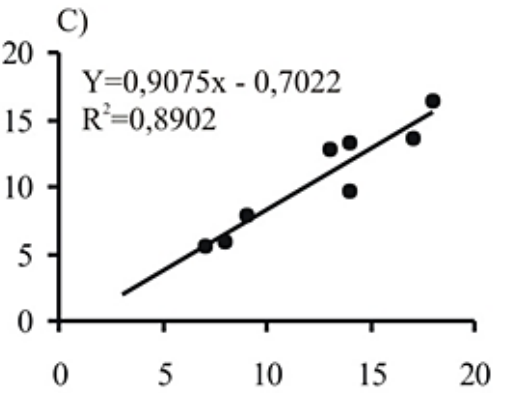

FIGURA 3: Modelos lineares ajustados entre Pi e P considerando dados dos dois anos hidrológicos (A), períodos chuvosos (B) e períodos secos (C).

FIGURE 3: Linear regression models adjusted for Pi and $\mathrm{P}$ considering data sets from the two hydrological years (A), dry seasons (B) and rainy seasons (C). 
encontraram valores de 1,4 $\mathrm{mm}$ para matas ciliares, enquanto Oliveira et al. (2008) estimaram valores de 1,6 mm para uma floresta tropical da Amazônia.

Por outro lado, quando se ajustaram os dados separadamente em função apenas do período chuvoso (B) e seco (C), para os dois anos hidrológicos, foram observadas alterações significativas da quantidade de água armazenada pelo dossel vegetativo. Assim, nos períodos chuvoso e seco, a capacidade de armazenamento do dossel foi de 1,35 (Figura 3B) e $0,77 \mathrm{~mm}$ no período seco (Figura 3C), respectivamente. Neste aspecto, notase que a capacidade de armazenamento de água do dossel no período chuvoso foi significativamente superior ao do período seco.

Lima (2008) relata que a capacidade de armazenamento do dossel é influenciada pela espécie e pela parte aérea da biomassa. Segundo o autor, a folha apresenta baixa capacidade de retenção de água em sua superfície, sendo, portanto, sua capacidade de armazenamento influenciada pelo seu tamanho, sua configuração e composição e pela viscosidade e pressões externas reinantes (precipitação, ventos, etc.) sobre a superfície foliar. Assim, estes fatores em conjunto provocam uma tensão superficial entre a superfície foliar e a água existente na folha, sendo, portanto, a retenção de água na superfície foliar regida pelo equilíbrio entre a tensão superficial e a força de gravidade. Segundo Park e Cameron (2008), a capacidade de armazenamento de água pelo dossel é especialmente relacionada à área de superfície da folha e às variáveis similares, tais como o índice de área foliar (IAF).

Estringana et al. (2010) relatam que a capacidade de armazenamento de água da maioria das plantas deve ser determinada por variáveis que são de complexa caracterização, tais como variáveis dendrométricas, pubescência e rugosidade das folhas e ângulo de orientação do pecíolo. Em algumas espécies, a pubescência é considerada a variável que apresenta maior influência no processo da capacidade de armazenamento de água pelo dossel (LEVIA e FROST, 2006).

Em um estudo detalhado visando à determinação da capacidade de armazenamento de água pelo dossel de nove espécies de arbustos do Mediterrâneo com diferentes características anatômicas e morfológicas, Estringana et al. (2010) observaram que os arbustos que armazenaram maior conteúdo de água por unidade de biomassa foram as espécies que apresentaram maior pubescência das folhas e dos caules. Em contrapartida, as espécies que armazenaram menor quantidade de água foram as que apresentaram menores níveis de pubescência. Além disso, os mesmos autores perceberam que as espécies que apresentaram menor capacidade de armazenamento de água foram influenciadas pela orientação das folhas. No mesmo estudo, também se constatou que a espécie que apresentou menor capacidade de armazenamento de água do dossel foi a que apresentou maior IAF.

De acordo com estas inferências, constatase que apesar da capacidade de armazenamento estar relacionada a uma série de fatores, no caso da MBMA, com formação florestal semidecidual, a maior capacidade de armazenamento de água no período chuvoso pode ser atribuída à maior regeneração vegetal nesta época. Neste mesmo aspecto, a menor capacidade de armazenamento de água na MBMA no período seco está relacionada à menor área do dossel vegetativo proporcionada pela queda das folhas nesta época, ocasionando menor capacidade de armazenamento do dossel da Mata. Além disso, as inferências apontam que a variabilidade sazonal da capacidade de armazenamento de água na Mata Atlântica pode estar associada também às características fisiológicas e morfológicas da floresta não avaliadas neste estudo.

Nesse sentido, observa-se que a capacidade de armazenamento de água em ambiente de Mata Atlântica é um assunto relativamente complexo. Esta complexidade ocorre devido à interação dos processos relacionados à morfologia e à fisiologia da floresta, associados à variabilidade sazonal das precipitações. Assim, é importante destacar a relevância de estudos nesta linha de pesquisa, uma vez que permite melhor descrição e entendimento dos processos hidrológicos em bacias hidrográficas constituidas por ecossistemas florestais.

\section{Índice de vegetação por diferença normalizada (IVDN) para os períodos chuvoso e seco na MBMA, Serra da Mantiqueira, MG}

Na Figura 4 estão apresentados os mapas das diferenças de IVDN reclassificados correspondentes aos períodos chuvoso e seco de cada ano hidrológico. Assim, as classes simbolizadas em cinza-claro e em preto sinalizam uma possível perda e regeneração vegetal, respectivamente.

Analisando-se a referida Figura, observa-se que, no período úmido do ano hidrológico de 09/10 (Figura 4A), as diferenças do IVDN sinalizaram regeneração vegetal em praticamente $15 \%$ da área, 


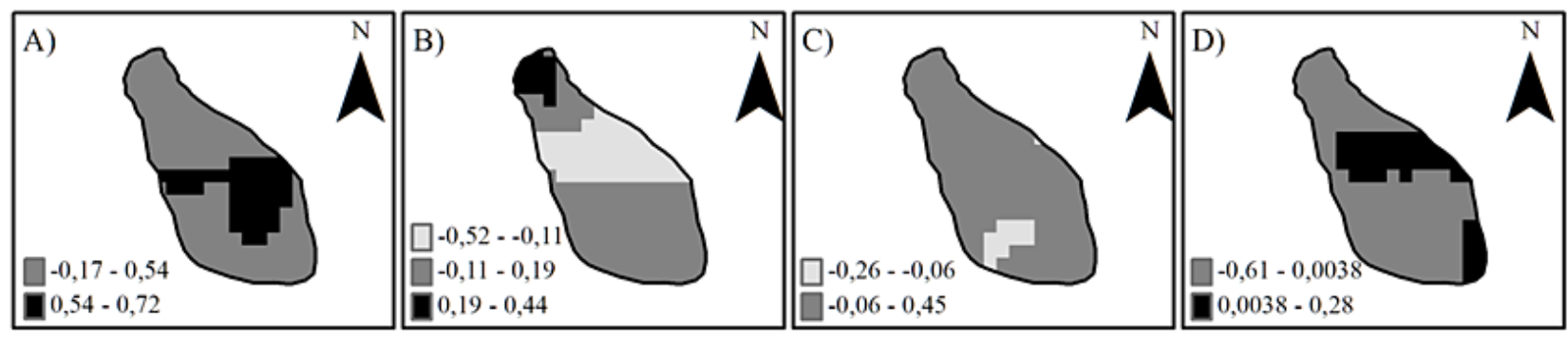

FIGURA 4: Diferenças do índice de vegetação por diferença normalizada (IVDN) correspondentes aos períodos chuvoso e seco, para os anos hidrológicos 2009/2010 (A, B) e 2010/2011 (C, D).

FIGURE 4: Differences between normalized difference vegetation indexes (NDVI) from dry and rainy seasons of 2009/2010 (A, B) and 2010/2011 (C, D) hydrological years.

com diferenças de IVDN entre 0,54 e 0,72 . No período seco (Figura 4B) há indicação de perda de vegetação $(-0,52$ a $-0,11)$ em, aproximadamente, $20 \%$ na região central da MBMA e uma leve regeneração vegetal $(0,19$ a 0,44$)$, em torno de $5 \%$, na face norte da bacia.

No ano hidrológico 10/11, observou-se comportamento inverso, ou seja, no período chuvoso (Figura 4C), houve ligeira perda de vegetação $(-0,26$ a 0,06$)$ numa pequena parcela da MBMA (em torno de 5\%) e, no período seco (Figura 4D), apresentou ligeira regeneração $(0,0038$ a 0,28$) \mathrm{em}$, aproximadamente, $10 \%$ da área da floresta. Além disso, nota-se que as diferenças de IVDN atuaram de forma mais representativa no ano hidrológico de 09/10, abrangendo maior área geográfica, com maior magnitude das diferenças de IVDN. Desse modo, observa-se maior variabilidade do padrão da dinâmica temporal da floresta no ano hidrológico de 09/10. Além disso, em função das diferenças dos valores de IVDN, observam-se variações sazonais e intra-anuais deste fragmento de Mata Atlântica.

Correlacionando-se os dados de precipitação interna acumulados para os períodos chuvoso e seco (Figura 2B) com as diferenças do IVDN (Figura 4), considerando-se a estação seca e úmida para ambos os anos hidrológicos, constatou-se correlação plausível entre os dados. Para os períodos nos quais as diferenças de IVDN sinalizaram maior perda da vegetação, ou seja, período seco do ano hidrológico 09/10 (Figura 4B) e período úmido do ano hidrológico 10/11 (Figura 4C), tanto na magnitude do índice quanto na porcentagem da área florestada, o percentual de precipitação interna foi consideravelmente maior. Isto é, as diferenças do IVDN do período seco do ano hidrológico 09/10 (Figura 4B) e período úmido do ano 10/11 (Figura
4C), os quais sinalizaram maior perda de vegetação, corresponderam aos períodos em que houve maior parcela de precipitação convertida em precipitação interna, ou seja, $95 \%$ e $81 \%$, respectivamente. De forma semelhante, nos períodos em que as diferenças de IVDN indicaram regeneração da vegetação (período úmido do ano hidrológico 09/10 - Figura 4A e período seco do ano hidrológico 10/11Figura 4C), a parcela de precipitação convertida em precipitação interna foi relativamente menor, com 75 e $79 \%$, respectivamente.

Este fato mostra que a parcela de precipitação incidente que é convertida em precipitação interna está diretamente relacionada aos processos responsáveis pelo crescimento da floresta. De acordo com Sprintsin et al. (2007), um dos principais fatores relacionados a esses processos é o índice de área foliar, o qual está diretamente relacionado à parcela interceptada pelo dossel, à fotossíntese da planta e à diminuição da serrapilheira.

Desta forma, observa-se que as diferenças de IVDN apresentaram relações diretas com os processos responsáveis pelas mudanças nos ecossistemas, influenciando no comportamento da dinâmica espacial e temporal do dossel vegetativo da Mata Atlântica ao longo dos dois anos hidrológicos monitorados e no comportamento da partição da precipitação incidente.

\section{CONCLUSÕES}

A precipitação interna total no período analisado correspondeu a $79 \%$ da precipitação incidente total. A parcela de água que atravessa o dossel vegetativo da Mata Atlântica e efetivamente atinge a superfície do solo, contribuindo para o 
abastecimento dos aquíferos, é proporcionalmente maior em períodos com menores totais precipitados, podendo-se associar tal comportamento à formação florestal semidecídua da Mata Atlântica.

A capacidade de armazenamento de água do dossel vegetativo da Mata Atlântica é 1,58 mm, considerando o ano hidrológico como um todo. Considerando apenas eventos do período chuvoso, este valor é $1,35 \mathrm{~mm}$ e para o período seco, de $0,77 \mathrm{~mm}$, sendo que este comportamento pode estar associato à maior regeneração vegetal no período chuvoso.

As diferenças do índice de vegetação por diferença normalizada (IVDN) apresentaram correlação plausível com os valores de precipitação interna, tanto para as estações secas quanto para as úmidas, dos anos hidrológicos analisados, apresentando maior percentual de precipitação interna nos períodos em que os valores de IVDN sinalizaram maior perda de vegetação, podendo associar este comportamento aos processos responsáveis pelo crescimento da Mata Atlântica.

\section{AGRADECIMENTOS}

O presente trabalho foi realizado com o apoio da CAPES, entidade do Governo Brasileiro voltada para a formação de recursos humanos.

\section{REFERÊNCIAS BIBLIOGRÁFICAS}

ALLEN, R. G. et al. Surface Energy Balance Algorithm for Land: advanced training and users manual. Idaho: [s. n.], 2002. 98 p.

ARCOVA, et al. Precipitação efetiva e interceptação das chuvas por floresta de Mata Atlântica em uma microbacia experimental em Cunha-SP. Revista Árvore, v. 27, n. 2, p. 257-262, Mar./Abr. 2003.

BARET, F. ; GUYOT, G. Potentials and limits of vegetation indicesfor LAI and APAR assessment,

Remote Sensing of Environment, v. 35, n. 2-3, p. 161-173, Feb./Mar. 1991.

CARDOSO, C. A. et. al. Precipitação interna de um fragmento de mata atlântica no município de Viçosa-MG. In: REUNIÃO BRASILEIRA DE MANEJO E CONSERVAÇÃO DO SOLO E DA ÁGUA, 1., 2002, Cuiabá. Anais.... Cuiabá: SBCS, 2002. 1 CD ROM.

CASTRO, P. S et al. Interceptação da chuva por mata natural secundária na região de Viçosa, MG. Revista Árvore, Viçosa, MG, v. 7, n. 1, p. 76-89, Jun. 1983.
CHANDER, G.; MARKHAM, B. L. Revised Landsat-5 thematic mapper radiometric calibration. IEEE Geoscience and Remote Sensing Society, v. 4, n. 3, July 2007.

CHANDER, G.; MARKHAM, B. L. "Revised Landsat- 5 thematic mapper radiometric calibration procedures, and post-calibration dynamic ranges," IEEE Geoscience and Remote Sensing Society, v. 41, n. 11, p. 2674-2677, Nov. 2003.

CROCKFORD, R. H.; RICHARDSON, D. P. Partitioning of rainfall into throughfall, stemflow and interception: effect of forest type, ground cover and climate. Hydrological Processes, v. 14, n. 1617, p. 2903-2920, Nov./Dec. 2000.

CUARTAS, L. A. Estudo observacional e de modelagem hidrológica de uma micro-bacia em floresta não perturbada na Amazônia Central. 2008. 236 f.Tese (Doutorado em Meteorologia) Instituto Nacional de Pesquisas Espaciais, São José dos Campos, 2008.

CUARTAS, L. A. et al. Interception waterpartitioning dynamics for a pristine rainforest in Central Amazonia: marked differences between normal and dry years. Agricultural and Forest Meteorology, v. 145, n. 1-2, p. 69-83, Jul. 2007.

DAVID, T. S. et al. Intercepção da precipitação em árvores isoladas de Quercus rotundifolia Lam. Silva Lusitana, v. 10, n.1, p. 1-15, Jun. 2002.

DÍAZ, F. M. et al. Alteration of the hydrologic cycle due to forest clearing and its consequences for rainforest succession. Forest Ecology and Management, v. 244, n. 1-3, p. 32-40, June 2007.

DIETZ, J. et al. Rainfall partitioning in relation to forest structure in differently managed montane forest stands in Central Sulawesi, Indonesia. Forest Ecology and Management, v. 237, n. 1-3, p. 170-178, Dec. 2006.

ESTRINGANA， P. G.; BLAZQUEZ， N. A.; ALEGRE, J. Water storage capacity, stemflow and water funneling in Mediterranean shrubs. Journal of Hydrology, v. 389, n. 3-4, p. 363-372, Aug. 2010.

FERREIRA, S. J. F. et. al. Precipitação interna e interceptação da chuva em floresta de terra firme submetida à extração seletiva de madeira na Amazônia Central. Acta Amazonica, v. 35, n. 1, p. 55-62, Nov. 2005.

FOLHES, M. T. Modelagem da evapotranspiração para a gestão hídrica de perímetros de irrigação com base em sensores remotos. 2007. p. Tese (Doutorado em Sensoriamento Remoto), Instituto Nacional de Pesquisas Espaciais. São José dos 
Campos, 2007.

GASH, J. H. C. et al. Estimating sparse forest rainfall interception with an analytical model. Journal Hydrology, v. 170, n. 1-4, p. 79-86, Aug. 1995.

GERRITS, A. M. J. et al. Spatial and temporal variability of canopy and forest floor interception in a beech forest. Hydrological Processes, v. 24, n. 21, p. 3011-3025, Oct. 2010.

GRIP, H., FRITSCH, J.-M., BRUIJNZEEL, L.A., 2004. Soil and water impacts during forest conversion and stabilisation of new land use. In: Bonnell, M., Bruijnzeel, L.A. (Eds.), Forests, Water and People in the Humid Tropics. Cambridge University Press, Cambridge, p. 561-589.

GURGEL, H. C.; FERREIRA, N. J. Annual and interannual variability of NDVI in Brazil and its connections with climate. International Journal of. Remote Sensing, v. 24, n. 18, p. 3595-3609, 2003.

HERBST, M. et al. Measuring and modelling the rainfall interception loss byhedgerows in southern England. Agricultural and Forest Meteorology, v. 141, n. 1-4, p. 244-256, Nov. 2006.

HOLDER, C. D. Rainfall interception and fog precipitation in a tropicalmontane cloud forest of Guatemala. Forest Ecology and Management, Amsterdam, v. 190, n. 2-3, p. 373-384, Mar. 2004. HÖLSCHER, D. et al. The importance of epiphytes to total rainfall interception by a tropical montane rainforest in Costa Rica. Journal of Hydrology, v. 292, n. 1-4, p. 308-322, Jun. 2004.

HOLWERDA, F.; SCATENA, F. N.; BRUIJNZEEL, L. A. Throughfall ina Puerto Rican lower montane rainforest: a comparison of sampling strategies. Journal of Hydrology, v. 327, n. 3-4, p. 592-602, 2006.

HUXMAN, T. et al. Convergence across biomes to a common rain-use efficiency. Nature, v. 429, n. 2, p. 651-654, Jun. 2004.

INFOCLIMA - Boletim de Informações Climáticas do CPTEC/INPE. v. 18, n. 9, set. de 2011a.(www. cptec.inpe.br/infoclima).

JUNQUEIRA JUNIOR, J. A. et al. Continuidade espacial de atributos físico-hídricos do solo em sub-bacia hidrográfica de cabeceira. Ciência e Agrotecnologia, v. 32, n. 3, p. 914-922, Maio/Jun. 2008.

KOGAN, F. N. Application of vegetation index and brightness temperature for drought detection. Advanced Spa Research, v. 15, n. 11, 91-100,
1995.

LEVIA, D. F.; FROST, E. E. Variability of throughfall volume and solute inputs in wooded ecosystems. Progress in Physical Geography, v. 30, n. 5, p. 605-632, Oct. 2006.

LI, S. et al. Water quality in the upper Han River basin, China: the impacts of land use/land cover in riparian buffer zone. Journal of Hazardous Materials, v. 165, n. 1-3, p. 317-324, Jun. 2009.

LIMA, P. R. A.; LEOPOLDO, P. L. Quantificação de componentes hidrológico de uma mata ciliar, através do modelo e balanço de massas. Revista Árvore, Viçosa, v. 24, n. 3, p. 241-252, 2000.

LIMA, W. P. Hidrologia florestal aplicada ao manejo de bacias hidrográficas. São Paulo: Escola Superior de Agricultura " Luiz de Queiroz". Departamento de Ciências Florestais. Piracicaba. 2008. 2. ed, $245 \mathrm{p}$.

LOESCHER, H.W., et al. Spatial variation of throughfall volume in an old-growth tropical wet forest, Costa Rica. Journal of Tropical Ecology, v. 18, n. 3, p. 397-407, May 2002.

MELLO, C.R. et al. Sea surface temperature (SST) and rainfall erosivity in the Upper Grande River Basin, Southeast Brazil. Ciência e Agrotecnologia, v. 36, n. 1, p. 53-59, 2012.

MENEZES, M.D. Levantamento pedológico de hortos florestais e mapeamento digital de atributos físicos do solo para estudos hidrológicos. 2011. 225 p. Tese (Doutorado em Ciência do Solo)Universidade Federal de Lavras, Lavras, 2011.

MENEZES, et al. Dinâmica hidrológica de duas nascentes, associada ao uso do solo, características pedológicas e atributos físico-hídricos na sub-bacia hidrográfica do Ribeirão Lavrinha - Serra da Mantiqueira (MG). Scientia Forestalis, n. 82, v. 37, p. 175-184, Jun. 2009.

NEZLIN, N. P. et al. Inter-annual variability and interaction of remote-sensed vegetation index and atmospheric precipitation in the Aral Sea region. Journal of Arid Environments, v. 62, n. 4, p. 677-700, Set. 2005.

OLIVEIRA JÚNIOR, J. C.; DIAS, H. C. T. Precipitação efetiva em fragmento secundário da mata atlântica. Revista Árvore, v. 29, n. 1, p. 9-15, Jan./Fev; 2005.

OLIVEIRA, L. L. et al. Modelagem da interceptação na floresta nacional de caxiuanã, no leste da Amazônia. Revista Brasileira de Meteorologia, v. 23, n. 3, p. 318-326, Set. 2008.

OLIVEIRA FILHO, A. T. et al. Definição e delimitação de domínios e subdomínios das 
paisagens naturais do estado de Minas Gerais. In: SCOLFORO, J. R.; CARVALHO, L. M. T. (Ed.). Mapeamento e Inventário da Flora e dos Reflorestamentos de Minas Gerais. Lavras: UFLA, 2006. cap. 1, p.21-35.

PARK, A.; CAMERON, J. L. The influence of canopy traits on throughfall andstemflow in five tropical trees growing in a Panamanian plantation. ForestEcology and Management, v. 255, n. 5-6, p. 1915-1925, Abr. 2008.

SELLERS, P. J.; SCHIMEL, D. Remote sensing of the land biosphere and biochemistry in the EOS era: science priorities, methods and implementationEOS land biosphere and biochemical panels. Global and Planetary Change, v. 7, n. 4, p. 279-297, Jun.1993.

SPRINTSIN, M. et al. The effect of spatial resolution on the accuracy of leaf area index estimation for a forest planted in the desert transition zone. Remote Sensing of Environment, New York, v. 109, n. 4, p. 416-428, Aug. 2007.

STAELENS, J. et al. Rainfall partitioning into throughfall, stemflow, and interception within a single beech (Fagus sylvatica L.) canopy: influence of foliation, rain event characteristics, and meteorology. Hydrological Processes, v. 22, n. 1, p. 33-45, Jan. 2008.

TUCKER, C. J. Red and photographic infrared linear combinations for monitoring vegetation - Remote Sensing Environment, v. 8, n. 2, p. 127-150, May 1979.

TUCKER, C. J.; SELLERS, P. J. Satellite remote sensing of primary production. International Journal of Remote Sensing, v. 7, n. 11, p. 1395-1416, 1986.

VALENTE, F.; DAVID, J. S.; GASH, J. H. C. Modelling interception loss for two sparse eucalypt and pine forest in central Portugal using reformulated Rutter and Gash analytical models. Journal of Hydrology, v. 190, n. 1-2, p. 141-162, Mar. 1997.

WANG, Q. et al. Similarities in ground and satellitebased NDVI time series and their relationship to physiological activity of a Scots pine forest in Finland. Remote Sensing of Environment, New York, v. 93, n. 1-2, p. 225-237, Oct. 2004. 